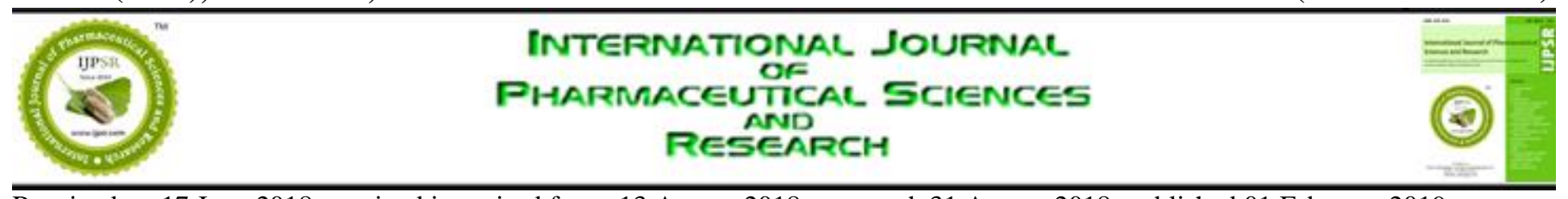

Received on 17 June 2018; received in revised form, 13 August 2018; accepted, 31 August 2018; published 01 February 2019

\title{
NUTRITIONAL STATUS OF CHILDREN WITH CONGENITAL HEART DISEASE
}

\author{
Oday Faris Washeel ${ }^{*} 1$ and Eqbal Ghanim Ali Ma'ala ${ }^{2}$ \\ Department of Pediatrics Health ${ }^{1}$, Nursing College, Al-Muthanna University, Samawah, Iraq. \\ Department of Pediatrics Health ${ }^{2}$, Nursing College, University of Baghdad, Baghdad, Iraq.
}

Keywords:

Nutritional status, Congenital heart disease, Children

Correspondence to Author:

Dr. Oday Faris Washeel

Ph.D.,

Department of Pediatrics Health,

Nursing College, Al-Muthanna

University, Samawah, Iraq.

E-mail: odayalfartosy@yahoo.com
ABSTRACT: Congenital heart disease (CHD) is a defect in the heart or major blood vessels that are present in children at birth \& CHD it occurs in approximately $1 \%$ of live births in developed countries. Infants and children with CHD exhibit a range of delays in weight gain and growth. Objective: To find out the relationship between the children with CHD nutritional status and their socio-demographic characteristics. Methodology: Non-probability (purposive) sample of (65) were selected of 225 children who visit the heart center during the period of conducting the pilot study, previously diagnosed with congenital heart disease. Results: The children with congenital heart disease have $(32.3 \%)$ suffered from underweight by weight for age, a highly significant relationship between weight for age index and gender. (64.6\%) of study sample suffered from wasting with weight for height, a significant high association between the premature baby " is wasting" and children with CHD. (78.5\%) Suffered from stunting with height for age. Almost half of the study sample suffered from malnourished $(49.2 \%)$ by measuring BMI for age, the highly significant association for the children with congenital heart disease and family's residency. Recommendation: The study recommended an establishment of feeding unit, located at heart disease hospitals and health centers, to teach the families the methods of feeding through teaching program for raising their awareness about child's feeding problems.
INTRODUCTION: Good nutrition is essential for survival, physical growth, mental development, performance, productivity, health and well-being across the entire life span from the earliest stages of fetal development, at birth, and through infancy, childhood, adolescence and on into adulthood. Chronic malnutrition in earlier years is responsible for widespread stunting and to adverse health and social consequences throughout the life span ${ }^{1}$. Infants and children are more likely to suffer from poor nutrition than compared to adults.

\begin{tabular}{|l|c|}
\hline QUICK RESPONSE CODE & DOI: \\
\hline & $\begin{array}{c}\text { To.13040/IJPSR.0975-8232.10(2).933-38 } \\
\text { The article can be accessed online on } \\
\text { www.ijpsr.com }\end{array}$ \\
\hline DOI link: http://dx.doi.org/10.13040/IJPSR.0975-8232.10(2).933-38 \\
\hline
\end{tabular}

There are some reasons for this: First one low nutritional stores: Newborn infants have low stores of fat and protein. The smaller the child, the fewer reserves of energy they have. This means that they can only cope with starvation for shortened periods. The second reason is high nutritional demands for growth: The amount of nutrition children require is greatest during infancy, because of their rapid growth during this period.

When the child is four months old, $30 \%$ of their nutritional intake is used for growth. By the age of 1 year, this falls to $5 \%$. The third reason is rapid development in the nervous system: the child's brain grows rapidly during the last four months of pregnancy and also during the first two years of the life. The connections between the nerve cells in the brain are being formed during this time. 
Therefore, good nutrition is important to ensure that this occurs properly. The fourth reason is Illness: the child's nutrition may be compromised following an episode of illness or surgery. The body's energy requirements are increased; thus intake of food and nutrients should be increased ${ }^{2}$.

Nutrition goals for infants \& children with congenital heart disease provide adequate calories and protein, taking into account potentially increased needs, promote normal weight gain and growth velocity, and promote oral feeding as able. Chronic illness or extended hospitalization may result in oral feeding challenges, maintain normal/near normal electrolyte levels. The child should watch closely for abnormalities if the child is on highly concentrated enteral feedings or certain medications ${ }^{3}$.

If a child has documented growth failure or is having difficulty meeting nutrition needs with an oral diet, supplemental tube feedings may be considered for additional energy and protein ${ }^{4}$.

Aggressive feeding strategies must be employed early with these children to prevent permanent growth disturbances because congenital cardiac abnormalities cause growth retardation as well as the strategies applied to help these children achieve normal weight 5 .

Congenital heart disease (CHD) is a defect in the heart or major blood vessels that are present in children at birth \& CHD it occurs in approximately $1 \%$ of live births in developed countries. Infants and children with CHD exhibit a range of delays in weight gain and growth. In some instances, the delay can be relatively mild, whereas in other cases, cause the failure to thrive ${ }^{6}$.

The term anthropometry refers to comparative measurements of the human body. The primary measures used as indices of growth and development include stature (length or height), weight, and head circumference (for young children). The secondary measures used to estimate body composition include triceps skinfold thickness, subscapular skinfold thickness, and midupper arm circumference ${ }^{7}$.

An important index of a child's nutritional status and should be monitored on a regular basis. Stature (length or height), weight, and head circumference are typically evaluated by comparing individual measurements to population data, represented by percentile curves on a growth chart. Current charts for assessment of growth have been constructed from cross-sectional studies in which large numbers of healthy children representing the racial and ethnic diversity of the USA were carefully measured at various ages and the data ranked in percentiles ${ }^{8}$.

The Methodology of the Study: A descriptive study was carried out on 65 children aged $0-<5$ years were selected according to specific criteria.

Anthropometric Measurements: The weight is measured for each child with CHD in the study. It is measured without shoes and light clothes as possible. The investigator used weight scale which is highly reliable and borrowed from the Iraqi Nutrition Research Institute, which is a gift from the United Nation Children's Fund (UNICEF) and has a capacity of $(188.8) \mathrm{kg}$.

Before using the scale, the investigator is checking the scale daily by weight a standard weight. During weighing, the scale was placed on a hard floor surface, and each participant was standing still in the center of the platform of the scale with the body weight evenly distributed between both feet. The height of children above two years is measured without shoes by using measuring tape of height two meters (UNICEF tape measure) it is already reliable. The individual should stand on a flat surface with weight distributed evenly on both feet, heals together and the head upward.

The arms are hanging freely to the sides, and the head, back, buttocks and heal are against the wall with the knee fully extended and line of vision parallel to the floor, while the child under two years was measured recumbent ${ }^{8}$. And anther anthropometric measurement like weight/age, weight/ height, height/age, and BMI/age was calculated by the scientific application program (WHO AnthroPlus) which obtained from Iraqi Nutrition Research Institute. According to the Dietary Guidelines for Americans 2010 \& Nutrition Research Institute in Baghdad body, the mass index is a measure of weight in kilograms $(\mathrm{kg})$ relative to height in meters (m) squared. 
Other anthropometric measurement categories for children according to Dietary Guidelines for
Americans 2010 \& Nutrition Research Institute in Baghdad represent as Table 1.

TABLE 1: ANTHROPOMETRIC MEASUREMENT CATEGORY FOR CHILDREN

\begin{tabular}{ccccc}
\hline z- score & \multicolumn{4}{c}{ Growth indicators } \\
\cline { 2 - 5 } & Ht./age & Wt./age & Wt./ht. & BMI/ age \\
\hline$+3 z$ score & Very long & Obese & Obese & Obese \\
+2 z score & $*$ & Overweight & Overweight & Overweight \\
+1 z- sore & $*$ & Potential serious weight gain & Potential serious weight gain & Potential weight gain \\
0z- score & $*$ & $*$ & $*$ & Normal weight \\
$-1 \mathrm{z}$ score & $*$ & $*$ & $*$ & Under weight \\
-2 z score & Stunting & Underweight & Wasting & Malnourished \\
$-3 z-$ score & Severe stunting & Severe underweight & Sever wasting & Sever Malnourished \\
\hline
\end{tabular}

Ref. Dietary Guidelines for Americans 2010\&Nutriton research Institute in Baghdad

*If signed point plotted on the line $\mathrm{z}$ score is regarded as the least serious category.

All anthropometric measurement was calculated by the scientific application program (WHO Anthro Plus) which obtained from Iraqi Nutrition Research Institute.

Questionnaire: The socio-demographic data sheet, consisted of ${ }^{10}$ items categorized as general information (children age and gender) and socioeconomic data (parents level of education, parents occupation status, type of family, the total number of family, number of rooms, house area, house content, and car possession). Question about the recent nutritional status of Children with Congenital Heart Disease \& Dealing with Food and Formula. Reliability of the questionnaire was determined through pilot study "test-retest" it was (0.82) and the validity determined through a panel of experts in the field.

Statistical analysis was performed using the Microsoft office excel 2007 and SPSS package (version 16). Chi-square statistics were used to determine the presence of an association between the variables.

\section{RESULTS:}

TABLE 2: DISTRIBUTION OF THE STUDY SAMPLE BY THEIR GENERAL INFORMATION

\begin{tabular}{cccc}
\hline & Variables & No & \% \\
\hline Gender & Male & 38 & 58.5 \\
& Female & 27 & 41.5 \\
Age & $0-2$ year & 44 & 67.7 \\
(years) & $<2->5$ years & 21 & 32.3 \\
& High & 3 & 4.6 \\
SESS & Middle & 21 & 32.3 \\
& Low & 41 & 63.1 \\
\hline
\end{tabular}

No. $=$ number $\%=$ percentile, SESS $=$ Socio-economic Status Score

The Table 2 shows (58.5\%) of the children were male, $(67.7 \%)$ their age is $0-2$ years old, and $(63.1 \%)$ of them coming from the low level of socioeconomic status score.

TABLE 3: STATISTICAL SUMMARY OF THE STUDIED ANTHROPOMETRIC MEASUREMENTS OF THE SAMPLE RELATIVE TO Z-SCORE

\begin{tabular}{ccccccccc}
\hline \multirow{2}{*}{ Z-score } & \multicolumn{2}{c}{ Weight/Age } & \multicolumn{2}{c}{ Weight/Height } & \multicolumn{2}{c}{ Height/Age } & \multicolumn{2}{c}{ BMI/Age } \\
\cline { 2 - 8 } & No & $\%$ & No. & \% & No. & \% & No. & \% \\
\hline +3Z-score & - & - & 2 & 3.1 & 1 & 1.5 & - & - \\
+2Z-score & 4 & 6.2 & - & - & - & - & 1 & 1.5 \\
+1Z-score & 3 & 4.6 & 3 & 4.6 & - & - & 9 & 13.8 \\
Median & 24 & 36.9 & 10 & 15.4 & 10 & 15.4 & 22 & 33.8 \\
-1Z-score & 13 & 20.0 & 8 & 12.3 & 3 & 4.6 & 1 & 1.5 \\
-2Z-score & 12 & 18.5 & 28 & 43.1 & 35 & 53.8 & 19 & 29.2 \\
-3Z-score & 9 & 13.8 & 14 & 21.5 & 16 & 24.6 & 13 & 20.0 \\
\hline
\end{tabular}

BMI=body mass index

This table shows the distribution of anthropometric studies through z-score, weight for age, that $(18.5 \%, 13.8 \%)$ either have underweight or sever underweight respectively, $(43.1 \%, 21.5 \%)$ have wasting or severe wasting respectively, weight for height $(53.8 \%, 24.6 \%)$ were stunting, or severe stunting in height for age and $(29.2 \%, 20.0 \%)$ were malnourished or sever malnourished in relation to BMI for age . 
TABLE 4: DISTRIBUTION OF THE FREQUENCIES, PERCENTAGES OF UNDERWEIGHT WASTING, STUNTING AND MALNOURISHED RELATIVE TO ANTHROPOMETRIC MEASUREMENT

\begin{tabular}{cccc}
\hline \multicolumn{2}{c}{ Anthropometric measurement } & Frequency & Percentage \\
\hline Weight for & Underweight & 21 & 32.3 \\
age & Not & 44 & 67.7 \\
Weight for & Wasting & 42 & 64.6 \\
height & Not & 23 & 35.4 \\
Height for & Stunting & 51 & 78.5 \\
age & Not & 14 & 21.5 \\
BMI for & Malnourished & 32 & 49.2 \\
age & Not & 33 & 50.8 \\
\hline
\end{tabular}

Table 4 shows the final result for general sample condition from calculated the $-2,-3$ for all z- score of anthropometric measurement to reflect the final scale of weight for age represent underweight, weight for height represent wasting, height for age represent stunting and malnourished for BMI for age. However, the other $\mathrm{z}$-scores of $-1,0,+1,+2$ and +3 represent no problems with anthropometric measurement and wasting, stunting, underweight and malnourished. That $(32.3 \%)$ were underweight in weight for age, $(64.6 \%)$ were wasting by weight for height, (78.5\%) were stunting by height for age, and almost half of the sample $(49.2 \%)$ has malnourished about BMI for age.

TABLE 5: SOCIO DEMOGRAPHICAL CHARACTERISTICS OF CHILDREN WITH CHD AND THEIR ASSOCIATION P VALUE BY ANTHROPOMETRIC MEASUREMENT

\begin{tabular}{cccc}
\hline Demographical Characteristic of children \& their families & Anthropometric measurement & P-value \\
\hline Gender & Male & Underweight weight/age & $0.021^{*} \mathrm{HS}$ \\
female & Low & & $0.049^{*} \mathrm{HS}$ \\
SES & Middle & Underweight weight/age & \\
& High & Wasting weight/height & $0.027^{*}$ \\
Premature & & & $\mathrm{HS}$ \\
All SDC* & Stunting height/age & NS* \\
SES* & Low & & $0.046^{*} \mathrm{HS}$ \\
& Middle & Malnourished BMI/age & \\
Residency & Urban & & $0.035^{*} \mathrm{HS}$ \\
& Rural & Malnourished BMI/age & \\
\hline
\end{tabular}

SES: socio demographical status; SDC: socio demographical characteristic, HS: high significant; NO: no significant

This table show the association between anthropometric measurement and some sociodemographical characteristics with p-value that represented high significant between underweight (weight for age) and gender male and low level of child's family SES, high significant association between premature and wasting (weight/height), high significant association between malnourished (BMI/age) and low level of child's family SES. While no significant between stunting (height/age) with all socio-demographical characteristics.

DISCUSSION: Table 2 indicates that two third of the sample in the age group of (0-2) years $(67.7 \%)$, is age $0-2$ the close stage of birth regarding the onset of the symptoms and the discovery of these cases of heart disease. The present study inconsistent with many studies like the nutritional status of children with CHD by Mitchell and others to assess the nutritional status of children with congenital heart disease in 48 children admitted to the hospital, and another study of feeding problems in children with CHD: the impact on energy and growth outcome to analyzed presence or absence of early feeding problem in 40 children, but these studies don't focus on the gender only age.

Table 3 indicated that study sample weight for age, weight for height, height for age and BMI for age, either have underweight or sever underweight $(18.5 \%, 13.8 \%)$ respectively, $(43.1 \%, 21.5 \%)$ have wasted or severe wasting respectively, weight for height $(53.8 \%, 24.6 \%)$ were stunting or severe stunting in height for age and $(29.2 \%, 20.0 \%)$ were malnourished or sever malnourished in relation to BMI for age.

A study supports this finding indicates that differences in fat and muscle areas are associated with prenatal and postnatal growth differences, For these reasons, it is recommended that assessment of nutritional status during growth period \& the children condition explain with reference to fat and muscle area, the calculations of fat and muscle area 
are easily performed through manual calculation and they can also be obtained by interpolation from published monograms ${ }^{10}$.

The final result for the present study sample in Table 4 revealed the general condition from calculated the $-2,-3$ for all z-score of anthropometric measurement and reflect the final scale of weight for age which shows and represents underweight, weight for height represent wasting, height for age represents stunting and malnourished for BMI for age. However, the other $\mathrm{z}$ scores of -1 , $0,+1,+2$ and +3 represent no problems with anthropometric measurement and wasting, stunting, underweight and malnourished. This result might be due to less amount of body required of nutrition, which related to $\mathrm{CHD} \&$ the children condition affected by the disease and prevents the child from getting enough nutrition from feeding.

The study by UN standing committee on nutrition (2014) fifth report on the world nutrition situation Geneva, WHO was reported of wasting, stunting and underweight for some countries in (0-5) old children; Afghanistan (16.1\%) is wasting, (47.6\%) have stunting a (49.3\%) have underweight; In India $(15.7 \%)$ is wasting, (44.9\%) have stunting a $(46.7 \%)$ have underweight; Ethiopia $(10.5 \%)$ is wasting, (51.5\%) have stunting a $(47.2 \%)$ have underweight.

Table 5 indicates that the male wasting accounted for $(21.1 \%), \&$ there is a highly significant relationship between the weight for age and the male gender at $\mathrm{P}$-value of $(\mathrm{p}=0.021)$. In addition Low Socio-Economic Status correlation statistically with weight for age (wasting) which accounted for $(33.3 \%)$ at $(\mathrm{p}=0.049)$, no significant association for wasting of the children with CHDs and their sociodemographic data, except for premature baby $(\mathrm{p}$-value $=0.027)$ and this result might be due to that premature baby already has problem with weight for height and those children are born preterm infants less than normal-weight and thus adversely affect the nature of their bodies in terms of textures and weight.

The study of the relationship between nutritional status and anthropometric measurements of children in Sierra Leonean factory displaced camp in 306 children of both gender aged from $1-5$ years conducted that weight is a sensitive index for the evaluation of nutritional status of children (Sierra Leone Journal of Biomedical Research, 2014). In the same table, there is no significant association noted between the children's sociodemographic characteristics and their nutritional status through anthropometric measurement (height for age) 'stunting.'

Anthropometry provides non-invasive, easy but yet valuable information on nutritional status. Anthropometric measures of most significance in children include weight and height (Smith and Brown, 2015; Joint FAO/WHO, 2016; Waterlow, 1972; Sudesh, 2006) weight-height ratio (Robinson and Jelliffe, 2016; Shantha et al., 2017; Sharma et al., 2016). A study, conducted by Gandhi and other study shows a relationship between the age groups and anthropometric measurements and the results of the study present highly significant in males relationship, while females have no significance (Gandhi et al., 2015). Malnourished of the children with CHDs and their sociodemographic data in Table 9 revealed no significant association between them except urban residency at p-value (0.035), \& family of low SES at p-value (0.046). A study carried out by Lopes and others, shows an association between the residency and anthropometric measurements and the results of the study present significantly in both genders (Lopes et al., 2017).

\section{ACKNOWLEDGEMENT: Nil}

\section{CONFLICT OF INTEREST: Nil}

\section{REFERENCES:}

1. World Health Organization Multicenter Growth Reference Study Group: WHO child standards based on length/height, weight, and age. Acta Paediatrica (suppl) 2017; 450: 76-85

2. Dwyer J: Harrisons Principles of Internal Medicine; Nutritional Requirements and Dietary Assessment. USA: The McGraw-Hill Companies 2017.

3. Nagel M: Update on congenital heart disease: Nutrition problems and solutions. Nutrition Focus 2017; 21(3): 1-5.

4. Wessell JJ: Cardiology. In: Samour PQ, Helm KK, eds. Handbook of Pediatric Nutrition, $3^{\text {rd }}$ ed. Boston MA: Jones and Bartlett Publishers 2016.

5. Wessell JJ: Cardiology. In: Samour PQ, Helm KK, eds. Handbook of Pediatric Nutrition, $3^{\text {rd }}$ ed. Boston MA: Jones and Bartlett Publishers 2015.

6. Norris MK and Hill CS: Nutritional issues in infants and children with congenital heart disease. Crit Care Nurs Clin North Am. 2015; 6: 153-163. 
7. Cole TJ: In Anthropometric Assessment of Nutritional Status, $3^{\text {rd }}$ ed. Himes, JH. Wiley-Liss, Inc., New York, 2017; 83-111.

8. Ulijaszek SJ and Mascie-Taylor CG: Anthropometry: the individual and the population, USA: Cambridge University Press, New York 2016; 67.

9. Pierpont ME: Genetic Basis for Congenital Heart Defects: Current Knowledge: A scientific statement from the American Heart Association Congenital Cardiac Defects Committee, Council on cardiovascular disease in the young. Circulation 2018; 115: 3015-3038.

10. Crocker $M$ and Yanovski J: Pediatric Obesity: Etiology and Treatment. Endocrinol Metab Clin North Am 2009; 38(3): 525-548. doi:10.1016/j.ecl.2017.06.007.

11. Norris MK and Hill CS: Nutritional issues in infants and children with congenital heart disease. Crit Care Nurs Clin NorthAm.2016; 6: 153-163.

12. Wong D, Eaton MH, Wilson D, Winkelstein ML and Schwartez P: Wongs essentials of pediatric nursing. $6^{\text {th }}$ edition, Mosby 2006; 156.
13. Zaal BAA, Musaiger AO and Souza RD: Dietary habits associated with obesity among adolescents in Dubai, United Arab Emirates. Nutr Hosp 2017; 24(4): 438-444.

14. Steinberger J, Jacobs DR, Raatz S, Moran A, Hong CP and Sinaiko AR: Comparison of body fatness measurements by BMI and skinfolds vs. dual-energy X-ray absorptiometry and their relation to cardiovascular risk factors in adolescents Int J Obes (Lond) 2016; 29: 1346-1352.

15. Cheuk DK, Wong SM, Choi YP, Chau AK and Cheung YF: Parents' understanding of their child's congenital heart disease. Heart 2015; 90(4): 435-9.

16. Waterlow JC: Classification and definition of proteincalorie malnutrition. Br Med. J. 2008; 3: 566-9.

17. Dogan Y: Nutritional status of patients hospitalized in the pediatric clinic. The Turkish Journal of Gastroenterology 2015; 16(4): 212-216.

18. Lopes TD, Ferreira DM and Pereira RA: Assessment of anthropometric indexes of children and adolescents with socio-demographic Data. Jornal de Pediatria 2018; 84(4): 350 .

\section{How to cite this article:}

Washeel OF and Ma'ala EGA: Nutritional status of children with congenital heart disease. Int J Pharm Sci \& Res 2019; 10(2): 933-38. doi: 10.13040/IJPSR.0975-8232.10(2).933-38.

All @ 2013 are reserved by International Journal of Pharmaceutical Sciences and Research. This Journal licensed under a Creative Commons Attribution-NonCommercial-ShareAlike 3.0 Unported License.

This article can be downloaded to ANDROID OS based mobile. Scan QR Code using Code/Bar Scanner from your mobile. (Scanners are available on Google Play store) 